\author{
Pathophysiology \\ of Haemostasis \\ and Thrombosis
}

\title{
Home Treatment of Deep Vein Thrombosis
}

\section{An Out-Patient Treatment Model with Once-Daily Injection of Low-Molecular-Weight Heparin (Tinzaparin) in 555 Patients}

\author{
Leif Lapidus J ens Börretzen Martin Fahlén Hans Grönlund Thomsen \\ Sverker Hasselblom Lars Larson Henrik Nordström Lennart Stigendal \\ Lotte Waller
}

Department of Internal Medicine, Sahlgrenska University Hospital, University of Göteborg, Göteborg, Sweden

\section{Key Words \\ Deep vein thrombosis . Home treatment . \\ Low-molecular-weight heparin}

\begin{abstract}
During a 22-month period, 555 consecutive patients at seven hospitals in the western part of Sweden with an acute deep vein thrombosis (DVT) not involving the iliac vein and not having pulmonary embolism were included in a study testing the efficacy of implementing outpatient treatment. For all patients with a confirmed diagnosis of acute DVT, a folder was used that contained two checklists with detailed instructions for further treatment, one for the doctor and one for the nurse, an information pamphlet for the patient and prepared prescriptions for low-molecular-weight heparin (LMWH) tinzaparin (Innohep ${ }^{\circledR}$ ) of 175 anti-Xa IU/kg body weight subcutaneously once daily and warfarin. Patients not requiring hospitalisation, according to strict guidelines, were then eligible for treatment as out-patients. Prior to release from the emergency department for home treatment, a nurse provided detailed information to the patient and administered the first tinzaparin injection. In 194 (35.0\%) out of 555 patients, the DVT was localised only in the
\end{abstract}

lower leg not reaching the popliteal vein. Factors predisposing to venous thromboembolism were identified in $35.0 \%$ of the patients. $332(59.8 \%)$ out of the 555 patients studied did not require hospitalisation and were therefore treated as out-patients. 140 of these patients (42.2\%) injected themselves, the injection was given by a relative in $63(19.0 \%)$ patients and by the community nurse in 129 (38.9\%). Six (1.8\%) patients reported a worsening of the DVT condition during the LMWH treatment period. No major bleedings were observed during the injection treatment period. Except for local minor skin bleedings at the injection site, only $3(0.9 \%)$ patients reported minor bleedings during the injection treatment period. Recurrences of venous thromboembolism during the first 2 months were reported in 9 patients $(2.7 \%)$ out of 332 patients who were sent home from the emergency department. Five (2.2\%) patients out of the 223 who were admitted to the hospital had an increased tendency to bleeding. Twelve patients (5.4\%) were hospitalised because of a pronounced local status, 26 (11.7\%) were senile, social factors were the reason for hospitalisation in $76(34.1 \%)$ and lack of time of the physician in 39 (17.5\%) of the patients. A pharmacoeconomic analysis found a cost reduction of $69 \%$ with the present model for home treatment compared with traditional in-hospital

\section{KARGER \\ Fax +41613061234 \\ E-Mail karger@karger.ch}

www. karger.com

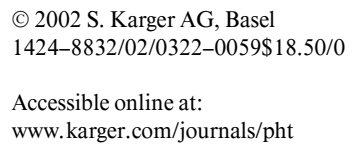

Dr. Leif Lapidus

Department of Medicine

Sahlgrenska University Hospital

S-413 45 Göteborg (Sweden)

Tel. +46 31342 1136/842 256, Fax +4631828 621, E-Mail leif.lapidus@swipnet.se 
treatment of DVT patients. We conclude that tinzaparin can be safely used at home by patients with DVT below the inguinal region and that the model used in the present study is cost-effective.

Copyright $@ 2002$ S. Karger AG, Basel

\section{Introduction}

Treatment of acute deep vein thrombosis (DVT) with a low-molecular-weight heparin (LMWH) has been shown to be effective and safe $[1,2]$ even when given on an outpatient basis [3-5]. The proportion of patients with DVT who are being treated at home varies considerably both internationally and regionally. The risk of bleeding and thrombotic complications is believed to be the most important reason for treatment in the hospital but another common reason for hospitalisation is that a thorough home treatment protocol is not available to the doctor in the emergency department or that the doctor does not have enough time to give the patient sufficient information for treatment at home.

We therefore believe that clear and structured guidelines/checklists for the doctor on duty at the emergency department including continuing education on guideline use are necessary to identify the true proportion of patients who can be safely treated at home.

The present study was conducted to answer the following questions:

(1) How many patients with a DVT not reaching the iliac vein can be treated at home, when clear guidelines, including strict criteria for treatment in hospital, are given to the doctor on duty?

(2) How often will an easily accessible community nurse give the injection, and how often will it be given by the patient or a relative?

(3) What are the frequencies of bleedings or recurrent thromboembolism with home treatment?

(4) What is the economic impact of home treatment of DVT?

\section{Subjects and Methods}

All patients suffering from an acute DVT not involving the iliac vein and not having symptoms of pulmonary embolism at seven hospitals in western part of Sweden were studied during a 22-month period.

The patients were referred to or consulted a doctor at the emergency department and after a clinical examination a referral to the Department of Radiology was considered.
The DVT was verified with venography or ultrasonography.

All patients were treated using standard guidelines:

When the patient returned to the Emergency Department with a positive DVT diagnosis, a folder was provided containing two checklists, one for the doctor (table 1) and one for the nurse (table 2), an information pamphlet for the patient and prepared prescriptions for LMWH and warfarin. The aim of the folder was to simplify the procedure for the doctor on duty. The doctor's checklist contained recommended laboratory analyses for detecting a tendency to bleeding and malignant disease. The coagulation investigation (antitrombin, protein $\mathrm{S}$, protein $\mathrm{C}$ and APCR) was performed after the completion of the warfarin treatment period. As shown in table 1 , the indications for X-ray examination of the lungs and gynaecological examination were shown on the doctor's checklist together with the indications for admission to the hospital. When referring the patient for in-hospital treatment, the doctor on duty at the emergency department was asked to record the reason for not sending the patient home. Detailed recommendations concerning pharmacological treatment including the duration of treatment were also given on the doctor's checklist. All patients were treated with tinzaparin (Innohep ${ }^{\circledR}$ ) at a fixed dose of 175 anti-X IU/kg body weight subcutaneously once daily without any monitoring, with a minimum of five injections and until the international normalized standardised ratio (INR) was $>2$. All patients received peroral anticoagulant treatment (warfarin) on the first day. The doses had to be entered in the patient's pamphlet by the doctor and were used as a written prescription to the nurse. If the first dose of tinzaparin was given after 3.00 p.m., it was reduced according to the checklist. Further, the checklist also included information about compression stockings, mobilisation and indications for contacting the community nurse.

Patients not requiring hospital treatment according to the checklist were treated as out-patients. The patient's consent for home treatment was not required. The study was approved by the ethical committee. A nurse with special training on venous thromboembolism was contacted and had the following tasks (table 2): administration of the first tinzaparin injection, collection of urine and faeces, providing information about the next monitoring of prothrombine time (at day 4), trying out the compression stockings and planning a follow-up appointment to meet the doctor at the thrombosis out-patient clinic after 2 months.

A few days after completion of the treatment with Innohep, the patient filled in a questionnaire to assess patient satisfaction.

A special computerised medical LMWH record for LMWH patients has been developed and is linked to an anticoagulant program which is now in use at 40 hospitals in Sweden. Thus the medical record, including social factors and details about the actual disease, was registered by the nurse in the computer for all patients on LMWH treatment.

\section{Results}

\section{Study Population}

Altogether 555 patients, 256 (46.1\%) men and 299 (53.9\%) women had a DVT not involving the iliac vein and were thus included in the study (table 3 ). The mean age was 65 years, range 21-95 years. A family history of venous thromboembolism was reported by $78(14.2 \%)$
Lapidus/Börretzen/Fahlén/
Grönlund Thomsen/Hasselblom/Larson/
Nordström/Stigendal/Waller 
Table 1. Checklist for doctor on duty

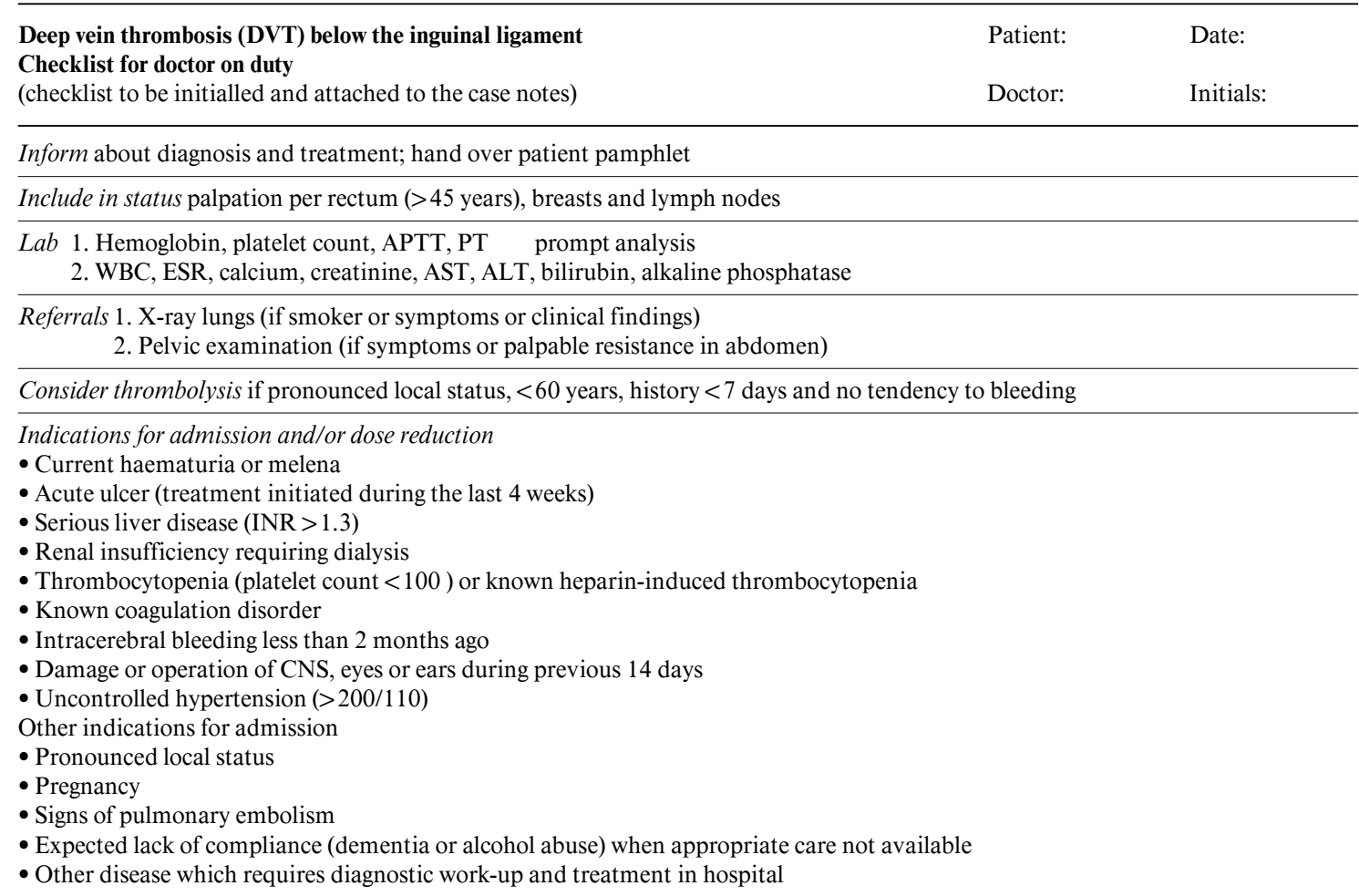

Prescription warfarin $2.5 \mathrm{mg} 100 \mathrm{tabl} \quad$ Doses to be entered in the patient pamphlet!

Day 1: $12.5 \mathrm{mg}$

Day 2: $7.5 \mathrm{mg}(5 \mathrm{mg}$ if $>70$ years or $<60 \mathrm{~kg})$

Day 3: $3.75 \mathrm{mg}(2.5 \mathrm{mg}$ if $>70$ years or $<60 \mathrm{~kg})$

Day 4: PT

Duration of treatment Idiopathic or irreversible risk factor: 6 months (longer if irreversible)

Reversible risk factor or calf vein thrombosis (below v. poplitea): 3 months

Prescription for Innohep graduated single-use syringes 20,000 anti-Xa IU/ml 6 syringes

\begin{tabular}{|c|c|c|c|c|c|c|c|c|}
\hline & $\mathrm{kg}$ & $\mathrm{ml}$ & & $\mathrm{kg}$ & $\mathrm{ml}$ & & $\mathrm{kg}$ & $\mathrm{ml}$ \\
\hline \multirow[t]{4}{*}{$0.5 \mathrm{ml}$} & 30 & 0.25 & \multirow[t]{4}{*}{$0.7 \mathrm{ml}$} & $60-65$ & 0.55 & \multirow[t]{4}{*}{$0.9 \mathrm{ml}$} & 85 & 0.75 \\
\hline & 35 & 0.30 & & 70 & 0.60 & & 90 & 0.80 \\
\hline & 40 & 0.35 & & 75 & 0.65 & & 95 & 0.85 \\
\hline & 45 & 0.40 & & 80 & 0.70 & & 100 & 0.90 \\
\hline
\end{tabular}

The first Innohep dose to be reduced according to the following:

$06-15 \mathrm{~h}$ full dose

$15-21 \mathrm{~h} \quad 75 \%$ dose

$21-03 \mathrm{~h} \quad 50 \%$ dose

$03-06$ h $\quad 25 \%$ dose

The dose is to be further reduced by $0.15 \mathrm{ml}$ if the patient has received a prophylactic dose (= Innohep 3,500 IU) prior to ultrasound/ phlebography during the last $3 \mathrm{~h}$

The following days, a full dose to be given in the morning until INR $>2$, minimum 5 injections.

If the first dose $=50 \%$ or less (including prophylactic dose) then at least 6 injections should be given.

The first injection is preferably administered by the thrombosis nurse, within 30 min after results of acute tests.

If pain is not pronounced, free mobilisation allowed even before first injection.

Thrombosis nurse at the anticoagulation clinic

Book visit before $15.00 \mathrm{~h}$ or next weekday $10.00 \mathrm{~h}$, ask the nurse at the emergency ward to phone!

The patient should bring the case notes (Innohep and warfarin doses to be recorded) and the red folder. (If the patient does not see the thrombosis nurse the same day, the case notes should remain in the dictation room.)

If friday after $16.00 \mathrm{~h}$ or weekend day, the patient can go home without compression stockings during the weekend but advised to have the leg frequently elevated and then go to the thrombosis nurse monday $10.00 \mathrm{~h}$.

Inform the patient that the district nurse can help if problems arise with the administration of the injection. 
Table 2. Checklist for thrombosis nurse

\begin{tabular}{|c|c|c|}
\hline $\begin{array}{l}\text { Deep vein thrombosis (DVT) below the inguinal ligament } \\
\text { Checklist for thrombosis nurse } \\
\text { (checklist to be initialled) }\end{array}$ & $\begin{array}{l}\text { Patient: } \\
\text { Nurse: }\end{array}$ & $\begin{array}{l}\text { Date: } \\
\text { Initials: } \\
\text { sign. }\end{array}$ \\
\hline
\end{tabular}

Normal response to tests for hemoglobin, platelet count, APTT and PT prior to Innohep injection

Innohep injection administered (to be given immediately upon arrival of normal test results) The district nurse to be contacted (if necessary)

$U-$ Erythrocytes, faeces - hemoglobin $\times 3$

Anticoagulation tag and anticoagulation pamphlet handed over

PT control on day 4 at the anticoagulation clinic (if weekend day: day 3 or day 5)

Ankle measure (b-measure): Calf measure (c-measure):

(after 30 min elevation on a wedge-shaped bolster)

Compression stockings tested

Appointment for follow-up with doctor after 2 months

Table 3. Characteristics of subjects

\begin{tabular}{|c|c|c|c|c|c|c|}
\hline \multirow[t]{2}{*}{ Characteristic } & \multicolumn{2}{|l|}{ Men } & \multicolumn{2}{|l|}{ Women } & \multicolumn{2}{|l|}{ Total } \\
\hline & $\mathrm{n}$ & $\%$ & $\mathrm{n}$ & $\%$ & $\mathrm{n}$ & $\%$ \\
\hline Included in the study & 256 & 46.1 & 299 & 53.9 & 555 & 100 \\
\hline $\mathrm{Age}^{1}$ & 62.4 & $(23-90)$ & 67.2 & $(21-95)$ & 65.0 & $(21-95)$ \\
\hline Family history of $\mathrm{DVT}^{2}$ & $37 / 253$ & 14.6 & $41 / 298$ & 13.8 & $78 / 551$ & 14.2 \\
\hline Major disease last 2 months ${ }^{3}$ & $121 / 254$ & 47.6 & $140 / 296$ & 47.3 & $261 / 550$ & 47.5 \\
\hline Physically active & $131 / 253$ & 51.8 & $151 / 298$ & 50.7 & $282 / 551$ & 51.2 \\
\hline DVT in lower leg only & $101 / 256$ & 39.5 & $93 / 299$ & 31.1 & $194 / 555$ & 35.0 \\
\hline Predisposing factors ${ }^{4}$ & $62 / 256$ & 24.2 & $53 / 297$ & 17.8 & $115 / 553$ & 20.8 \\
\hline \multicolumn{7}{|c|}{1 Data expressed as mean (range). } \\
\hline \multicolumn{7}{|c|}{2 DVT in parents, siblings or children. } \\
\hline \multicolumn{7}{|c|}{3 Includes chronic diseases. } \\
\hline \multicolumn{7}{|c|}{4 Except family history of DVT. } \\
\hline
\end{tabular}

patients. Other factors predisposing to venous thromboembolism (thrombophilia, prior history of venous thromboembolism, age $>75$ years, immobility, recent surgery, cancer, obesity, pregnancy or oral contraception) were identified in $115(20.8 \%)$ patients (table 3). In 194 (35.0\%) patients, the DVT was localised only to the lower leg not reaching the popliteal vein. Sixty $(10.8 \%)$ patients were smokers and $16(2.8 \%)$ reported alcohol problems.

\section{Home Treatment}

$332(59.8 \%)$ out of the 555 patients studied were treated at home (table 4). 140 of these patients (42.2\%) injected themselves, the injection was given by a relative in $63(19.0 \%)$ patients and $129(38.9 \%)$ patients were injected by the community nurse. $222(67 \%)$ of the patients treated at home had seven or less injections, but $15 \%$ needed 10 injections or more.

Only $7(2.1 \%)$ out of 330 patients who answered the questionnaire were not satisfied with the information from the nurse. Two (1.0\%) patients out of 203 who injected themselves or were injected by a relative reported problems with the injections. Six (1.8\%) patients reported impairment (pronounced local status or more pain) during the injection treatment period.

No major bleedings were observed during the tinzaparin treatment period. Except for local minor skin bleedings at the injection site, only $3(0.9 \%)$ patients out of 330 who answered the questionnaire reported minor bleedings during the injection treatment period. Recurrences during the first 2 months were reported in $9(2.7 \%)$ patients out 
Table 4. At-home treatment characteristics

\begin{tabular}{|c|c|c|c|c|c|c|}
\hline \multirow[t]{2}{*}{ Characteristic } & \multicolumn{2}{|l|}{ Men } & \multicolumn{2}{|l|}{ Women } & \multicolumn{2}{|l|}{ Total } \\
\hline & $\mathrm{n}$ & $\%$ & $\mathrm{n}$ & $\%$ & $\mathrm{n}$ & $\%$ \\
\hline Treated at home & $164 / 256$ & 64.1 & $168 / 299$ & 56.2 & $332 / 555$ & 59.8 \\
\hline Injection by patient & $62 / 164$ & 37.8 & $78 / 168$ & 46.4 & $140 / 332$ & 42.2 \\
\hline Injection by relative & $35 / 164$ & 21.3 & $28 / 168$ & 16.7 & $63 / 332$ & 19.0 \\
\hline Injection by community nurse & $67 / 164$ & 40.9 & $62 / 168$ & 36.9 & $129 / 332$ & 38.9 \\
\hline Number of injections & 6.3 & & 6.4 & & 6.3 & \\
\hline Satisfied with information & $158 / 162$ & 97.5 & $165 / 168$ & 98.2 & $323 / 330$ & 97.9 \\
\hline Impairment during injection period & $4 / 162$ & 2.5 & $2 / 167$ & 1.2 & $6 / 329$ & 1.8 \\
\hline Major bleedings (injection period) & $0 / 162$ & 0 & $0 / 168$ & 0 & $0 / 330$ & 0 \\
\hline Minor bleedings (injection period) ${ }^{1}$ & $2 / 162$ & 1.2 & $1 / 168$ & 0.6 & $3 / 330$ & 0.9 \\
\hline Recurrencies during 2 months & $4 / 164$ & 2.4 & $5 / 168$ & 3.0 & $9 / 332$ & 2.7 \\
\hline
\end{tabular}

1 Local minor skin bleedings at the place for injection excluded.

Table 5. In-hospital treatment characteristics

\begin{tabular}{|c|c|c|c|c|c|c|}
\hline \multirow[t]{2}{*}{ Characteristic } & \multicolumn{2}{|l|}{ Men } & \multicolumn{2}{|l|}{ Women } & \multicolumn{2}{|l|}{ Total } \\
\hline & $\mathrm{n}$ & $\%$ & $\mathrm{n}$ & $\%$ & $\mathrm{n}$ & $\%$ \\
\hline Treated at hospital & $92 / 256$ & 35.9 & $131 / 299$ & 43.8 & $223 / 555$ & 40.2 \\
\hline \multicolumn{7}{|l|}{ Reasons for hospitalisation } \\
\hline Bleeding & $2 / 92$ & 2.2 & $3 / 131$ & 2.3 & $5 / 223$ & 2.2 \\
\hline Local status & $7 / 92$ & 7.6 & $5 / 131$ & 3.8 & $12 / 223$ & 5.4 \\
\hline Suspicion of PE & $16 / 92$ & 17.4 & $22 / 131$ & 16.8 & $38 / 223$ & 17.0 \\
\hline Senility & $11 / 92$ & 11.9 & $15 / 131$ & 11.5 & $26 / 223$ & 11.7 \\
\hline Social factors & $33 / 92$ & 35.9 & $43 / 131$ & 32.8 & $76 / 223$ & 34.1 \\
\hline Lack of time & $17 / 92$ & 18.5 & $22 / 131$ & 16.8 & $39 / 223$ & 17.5 \\
\hline
\end{tabular}

$\mathrm{PE}=$ Pulmonary embolism.

of the 332 patients who were sent home from the Emergency Department. Two patients had pulmonary embolism and 7 had a new DVT. Eight of these 9 patients had a concurrent malignant disease. The recurrence occurred with INR values within the therapeutic range except in 2 patients who had marginally low INR values (1.8 and 1.9, respectively) at the time of the recurrence.

\section{Hospital Treatment}

Five (2.2\%) patients out of 223 who were admitted to the hospital had an increased tendency to bleeding according to the definition in the doctor's checklist (table 5). Twelve patients (5.4\%) were hospitalised because of a pronounced local status, $26(11.7 \%)$ were senile, social factors were the reason for hospitalisation in $76(34.1 \%)$ and not enough time to give information by the physician in $39(17.5 \%)$ of the patients.

Table 6 shows number of nights in hospital. Twentynine $(13.0 \%)$ patients out of 223 stayed one night in hospital whereafter they continued with home treatment with LMWH and warfarin.

\section{Cost Assessment}

A comparison was made between the cost of treating patients according to the present home treatment model (sending the patient home from hospital when possible) and traditional standard in-hospital treatment for 6 days.

The time required by the different personnel categories (physician, thrombosis nurse and community nurse) has been estimated based on past clinical experience of doc- 
Table 6. Number of nights for 223 patients treated in hospital

\begin{tabular}{|c|c|c|c|c|c|c|}
\hline \multirow{2}{*}{$\begin{array}{l}\text { Number } \\
\text { of nights }\end{array}$} & \multicolumn{2}{|c|}{ Men } & \multicolumn{2}{|c|}{ Women } & \multicolumn{2}{|c|}{ Total } \\
\hline & $\mathrm{n}$ & $\%$ & $\mathrm{n}$ & $\%$ & $\mathrm{n}$ & $\%$ \\
\hline 1 & 14 & 15.2 & 15 & 11.5 & 29 & 13.0 \\
\hline 2 & 22 & 23.9 & 24 & 18.3 & 46 & 20.6 \\
\hline 3 & 10 & 10.9 & 14 & 10.7 & 24 & 10.8 \\
\hline 4 & 7 & 7.6 & 12 & 9.2 & 19 & 8.5 \\
\hline 5 & 3 & 3.3 & 9 & 6.9 & 12 & 5.4 \\
\hline$\geq 6$ & 36 & 39.1 & 57 & 43.5 & 93 & 41.7 \\
\hline Total & 92 & 100 & 131 & 100 & 223 & 100 \\
\hline
\end{tabular}

Table 7. Cost description for the present model

\begin{tabular}{lr}
\hline & \multicolumn{1}{c}{ USD } \\
\hline Number of nights/patients in hospital \\
$1 / 29$ & 7,888 \\
$2 / 46$ & 25,024 \\
$3 / 24$ & 19,584 \\
$4 / 19$ & 20,672 \\
$5 / 12$ & 16,320 \\
$\geq 6 / 93$ & 151,776 \\
Total & 241,264 \\
\hline Extra costs for in-patients & \\
Physician & 76 \\
Thrombosis nurse & 171 \\
Community nurse & 766 \\
Disposable syringes & 3,492 \\
Total & 4,505 \\
\hline Extra costs for home treatment & \\
Physician & 3,302 \\
Emergency department nurse & 1,311 \\
Thrombosis nurse & 5,683 \\
Community nurse & 3,743 \\
Disposable syringes & 17,068 \\
Total & 31,107 \\
\hline Total cost & 276,876 \\
\hline & \\
\hline & \\
&
\end{tabular}

tors and nurses at our anticoagulation clinic. Based on experience, we have found that of the patients who required injection assistance by a nurse, $20 \%$ had home visits by a community nurse and $80 \%$ came to the community nurse out-patient clinic for help. A home visit is estimated to take $40 \mathrm{~min}$ for the nurse including travel time, while a visit at the clinic takes 15 nursing minutes. Vehicle costs are included in the calculations for home visits. We have based our cost calculations on our findings in this article that $38.9 \%$ of the home-treated patients required injection assistance by a community nurse after leaving hospital.

\section{Costs for Standard In-Hospital Treatment} (555 Patients Admitted to Hospital for 6 Days)

We have calculated the cost based on a 6-day hospital stay for the 555 patients participating in this study.

Information on the total cost of hospital care SEK 2,719 ( $=272$ USD) per patient and day, was provided by the Economy Department of Sahlgrenska University Hospital. This covers all costs including staff time for doctors and nurses, laboratory tests and drugs.

If all the 555 patients had been admitted for 6 days each, the total treatment cost would have been $555 \times 6 \times$ $272=905,760$ USD .

\section{Costs for Present Model}

(223 Patients Admitted to Hospital 1- to 6-Day Stays)

Costs for In-Hospital Patients. For comparison, costs for the present model were determined. In the current study, 223 patients were admitted to hospital with varying lengths of hospital stay. The total cost of in-hospital care for these 223 patients, with a total of 887 ward days, was $887 \times 272=241,264$ USD based on a daily cost of hospital care at 272 USD as above (table 7).

Additional Costs for the 130 Patients (of 223) Who Were Admitted to Hospital for 1-5 Days. These extra costs are added because discharge from hospital occurred during the injection treatment period and reflects the extra time required with the thrombosis nurse for consultation, injection by the community nurse and consultation with a physician. We estimated that $25 \%$ of the patients who were discharged from the hospital during the first 5 days needed extra consultation time with the thrombosis nurse, mean time per patient being estimated at $20 \mathrm{~min}$.

Based on a time cost for the thrombosis nurse (including pay roll tax) of 15.8 USD per hour the cost for these consultations was estimated at 171 USD.

The cost for the community nurse giving the injections was calculated at 766 USD (51 patients, 140 visits) also based on the rate of 15.8 USD per hour and taking vehicle costs into consideration (estimated mean: $8 \mathrm{~km}$ per patient, $0.13 \mathrm{USD} / \mathrm{km}$ ).

Similarly, additional telephone consultation with the physician for these 130 patients was calculated to 76 USD based on an estimation that $10 \%$ of the patients would need extra telephone consultations for $10 \mathrm{~min}$ and on a 
time cost for the physician of 35.1 USD. Additional cost for disposable syringes is estimated at 3,492 USD.

Costs for 332 Patients Sent Home from the Emergency Department. 332 of the patients were sent home directly from the emergency department. We estimated extra physician consultation time (compared with patients who were admitted to the hospital) for these patients to be $15 \mathrm{~min} /$ patient (in the Emergency Department) and 10min telephone contact with about $20 \%$ of the patients during the first week. Total cost for extra physician contact time is 3,302 USD. The nurse in the Emergency Department was estimated to need $15 \mathrm{~min}$ extra per patient at a total cost of 1,311 USD. The thrombosis nurse's initial time required per patient is calculated to be 60 min with an additional 20 min estimated for $25 \%$ of the patients with a total cost of 5,683 USD. Costs for the community nurse are estimated to be 3,743 USD. Additional costs for disposable syringes are estimated to be 17,068 USD.

The total cost for the 555 patients in the described model is thus $276,876 \mathrm{USD}$; the saving thus amounts to 628,884 USD (69.4\%) compared to conventional in-hospital treatment.

\section{Discussion}

As far as we know, previous studies have required patient consent before the implementation of home treatment. However, based on positive results from such studies [3-5], the patients were not given that possibility in our study. If the physician on duty determined that the patient could receive home treatment, following strict guidelines, then the patient was not admitted to hospital care. Therefore the results of this study were not steered by individual patients' concerns of being able to carry out their own treatment in the home setting. The current study confirms previous studies' findings that out-patient treatment is cost effective which further points to the importance of the determination of the proportion of patients with DVT that can be treated in the home setting. During the study period all patients with DVT were included in the study and since informed consent was not required by the study design we were able to determine the eligibility for home treatment based solely on welldefined criteria for hospital admission.

Nearly $60 \%$ (332 out of 555) of the patients could be sent home directly from the Emergency Department and another 99 patients $(17.8 \%)$ were discharged after only $1-$ 3 days of in-hospital treatment. Tendency for bleeding was given as reason for hospital admission in a few cases while social factors and lack of time available to the doctor on duty was a more common reason. Taking these factors into account, we therefore estimate that home treatment may be the appropriate means of treatment for more than $60 \%$ of patients with DVT not reaching the iliac vein.

The purpose of using a patient folder containing detailed checklists for the physician on duty and for the thrombosis nurse is to provide clear criteria for hospital admission and to reduce the risk of missing important steps in determining eligibility for out-patient treatment for the physician and the nurse when sending the patient home from the Emergency Department. The quality of the information received by the patient was judged to be acceptable by $98 \%$ of the patients as determined by a questionnaire. The proportion of patients who could selfinject or were injected by a relative was over $60 \%$. Access to a community nurse for injection assistance $(40 \%$ of patients) is of importance for the success of such a programme and if such a service is not available then a patient may be forced to visit the hospital on a daily basis for injection assistance.

We found that recurrencies during current treatment with anticoagulants were nearly always in patients who also had cancer.

Since we did not have a control group, we are not able to assess changes or improvements in the quality of life experienced under home treatment rather than in hospital. On the other hand, the cost estimates show a considerable economic advantage of utilising home treatment, as we did in the present study.

In conclusion, we found that our method of treating DVT with structured instructions for duty physician and thrombosis nurses was safe and cost saving. Training of doctors and nurses is imperative as well as the establishment of a network of community nurses. We believe that home treatment of DVT will have all the requirements to be a standard treatment form for most DVT patients.

\section{Acknowledgements}

The collection and analyses of data were supported by grants from Leo Pharma AB, Malmö, Sweden. 


\section{References}

1 Hull RD, Raskob GE, Pineo GF, Green D, Trowbridge AA, Elliott CG, Lerner RG, Hall J, Sparling T, Brettell HR, Norton J, Carter CJ, George R, Merli G, Ward J, Mayo W, Rosenbloom D, Brant R: Subcutaneous low-molecular-weight heparin compared with continuous intravenous heparin in the treatment of proximal-vein thrombosis. N Engl J Med 1992;326: 975-982.

2 Lindmarker P, Holmström M, Granqvist S, Johnsson H, Lockner D: Comparison of oncedaily subcutaneous Fragmin with continuous intravenous unfractionated heparin in the treatment of deep vein thrombosis. Thromb Haemost 1994;72:186-190.

3 Stockelberg D, Hansson E, Jonsson T: Treatment of deep vein thrombosis with low molecular weight heparin at patient's home. J Thromb Thrombolysis 1998;6:169-171.
4 Levine M, Gent M, Hirsh J, Leclerc J, Anderson D, Weitz J, Ginsberg J, Turpie AG, Demers C, Kovacs M: A comparison of low-molecular-weight heparin administered primarily at home with unfractionated heparin administered in the hospital for proximal deep-vein thrombosis. N Engl J Med 1996;334:667-681.

5 Koopman MM, Prandoni P, Piovella F, Ockelford PA, Brandjes DP, van der Meer J, Gallus AS, Simonneau G, Chesterman CH, Prins MH: Treatment of venous thrombosis with intravenous unfractionated heparin administered in the hospital as compared with subcutaneous low-molecular-weight heparin administered at home. N Engl J Med 1996;334:682-687.
Lapidus/Börretzen/Fahlén/

Grönlund Thomsen/Hasselblom/Larson/ Nordström/Stigendal/Waller 